\title{
A Macroeconomic Perspective on Border Taxes
}

\begin{abstract}
The debate on corporate tax reform in the United States has included arguments for a border-adjustment tax that would effectively raise the tax on imported inputs and provide a subsidy to exports. This policy is equivalent to other uniform border taxes, such as a combined import tariff and export subsidy, and a uniform value-added tax and payroll subsidy. In this paper, I argue that, contrary to popular arguments, such taxes are not neutral in either the short run or the long run, and they have significant consequences for international trade.
\end{abstract}

ax policy that treats domestically produced goods differently from foreign-produced goods has long been a part of the arsenal of policymakers. These "border taxes" can be explicit, and take the form of import tariffs and export subsidies; or they can be more subtle, in the form of value-added taxes (VAT) and payroll tax cuts. More recently, discussions of corporate tax reform in the United States have included proposals (Auerbach and others 2017) for a border-adjustment tax (BAT) that would disallow deductions of imported input costs from corporate revenue when computing taxable corporate profits, and would exclude export revenue from taxation.

In some situations, these policies have been used as a tool to stimulate economies. Famously, in 1931 John Maynard Keynes proposed in the Macmillan Report to the British Parliament that a combination of an import

Conflict of Interest Disclosure: The author received financial support for this work from the National Science Foundation under grant no. 1628874. With the exception of the aforementioned, the author did not receive financial support from any firm or person for this paper or from any firm or person with a financial or political interest in this paper. She is currently not an officer, director, or board member of any organization with an interest in this paper. No outside party had the right to review this paper before publication. 
tariff and an export subsidy be used to mimic the effects of an exchange rate devaluation while maintaining the gold pound parity (Committee on Finance and Industry 1931). Emmanuel Farhi, Gita Gopinath, and Oleg Itskhoki (2014) demonstrate the equivalence of the VAT-payroll tax swap policy to replicate the effects of a nominal exchange rate devaluation in economies with a fixed exchange rate. This analysis motivated the adoption of fiscal devaluation in France in 2012.

In other circumstances, as in the current debate on the BAT, the taxes are argued to be neutral-that is, having no effect on real allocations, as flexible exchange rates adjust to undo any real effect of the border tax. This prediction of neutrality has its origins in a classic result achieved by Abba Lerner (1936) in the field of international trade-since dubbed Lerner symmetry-and in its applications by Gene Grossman (1980) and Martin Feldstein and Paul Krugman (1990). According to this result, when prices and wages are fully flexible and trade is balanced, a combination of a uniform import tariff and an export subsidy of the same magnitude must be neutral, and thus have no effect on imports, exports, or other economic outcomes. This is because the tax leads to an increase in domestic wages relative to foreign wages (in a common currency), which in turn leaves the posttax price of imported goods unchanged relative to the price of domestically produced goods in all countries. That is, despite the higher tax on imports relative to domestically produced goods, the lower relative wage of foreign products leaves the price of imported goods relative to that of domestic goods unchanged. Similarly, on the export side, despite the export subsidy, the higher relative domestic wage leaves the relative price of domestic goods in foreign markets unchanged.

The assumptions of flexible prices and balanced trade are unrealistic, so the question becomes, under what circumstances do we retain neutrality when we depart from these assumptions? Omar Barbiero and others (2017) provide answers to this question, both qualitative and quantitative, for a BAT in a dynamic general equilibrium model. In this paper, I illustrate these arguments, using a simplified and static version of their model. The main takeaways are that, for neutrality to hold, all five of the following conditions must be satisfied.

First, when prices and wages are sticky, if there is symmetry in the passthrough of exchange rates and taxes into prices faced by buyers in each market, then neutrality is preserved. This symmetry is satisfied when prices are sticky in either the producer's currency or the local currency. In the former case, with fully preset prices, the pass-through of either is 100 percent, and consequently the exchange rate appreciation offsets taxes and there are 
no real effects. In the later case, the pass-through is zero in either case, and there are no real effects.

In reality, however, prices of traded goods are sticky in dollars regardless of origin and destination, as I argue in Gopinath (2015), which leads to a breakdown of neutrality. In this case, with fully preset prices, the exchange rate appreciation has no pass-through into import prices faced by domestic households and firms, while taxes have a 100 percent passthrough. On the flip side, the tax has no pass-through into export prices (in foreign currency), while the exchange rate has a 100 percent passthrough. In this case, the exchange rate appreciation leads to a decline in both imports and exports, and therefore to a decline in overall trade in the short run. These results hold more generally with staggered or statecontingent pricing.

One might question if sticky dollar pricing is a reasonable assumption in the face of large exchange rate changes when presumably more firms choose to adjust prices. This argument, however, fails to recognize that most exporters to the United States are also importers, and therefore a significant fraction of their costs are stable in dollars. Because the valueadded share of trade is much smaller than trade flows, and with most trade invoiced and sticky in dollars-even for trade with non-U.S. partnersthe scope to cut dollar prices is limited. Factors such as these explain why, despite a substantial and rapid appreciation of the dollar by 15 percent between the third quarter of 2014 and third quarter of 2015, the pass-through into border prices remained low, at about 35 percent (as opposed to a full pass-through of 100 percent).

Second, monetary policy should respond only to the output gap and inflation, and not to the exchange rate, to maintain neutrality. Even if sticky prices satisfy the assumptions for neutrality, if the monetary authority targets the exchange rate, it will generate real effects. This is precisely why the same border taxes are proposed as a stimulative policy tool under pegged exchange rates, while being neutral under flexible exchange rates. Relatedly, if foreign monetary authorities attempt to mitigate the depreciation of their currencies - a reasonable response-it will also lead to a breakdown in neutrality.

Third, when trade is not balanced, neutrality continues to hold as long as all international assets and liabilities are denominated in foreign currency. If, however, some international holdings are denominated in domestic currency, then neutrality is no longer preserved. Because foreign assets held by the United States are mostly denominated in foreign currency, while its foreign liabilities are almost entirely in dollars, this generates a 
large, one-time transfer to the rest of the world and a capital loss for the United States of about 10 percent of U.S. annual GDP (Farhi, Gopinath, and Itskhoki 2017). Barbiero and others (2017), however, show that because this transfer is a small fraction of U.S. wealth, the real impact is quantitatively relatively small.

Fourth, the implementation of the BAT must take the form of a onetime, permanent, and unanticipated policy shift for it to be neutral. Otherwise, expectations of a border tax in the future will cause immediate exchange rate appreciations that affect the portfolio choices of private agents, and therefore will have real consequences. Similarly, neutrality fails to hold if the policy is expected to be reversed and is therefore transitory, or if the other countries are expected to retaliate with their own policies in the future.

Fifth, neutrality requires border taxes to be uniform and to cover all goods and services. Service sectors, such as tourism, whose sales to foreigners take place within borders, are not treated the same as exports that cross borders, which in turn affects neutrality.

Failure of the first and second conditions in isolation generates deviations from neutrality only in the short run, in the standard Keynesian environment. This follows because all prices and wages are flexible in the long run, and monetary policy is irrelevant, returning us to Lerner symmetry. Failure of the remaining conditions generates deviations from neutrality even in the long run-that is, even when all prices and wages are flexible. I should emphasize that deviations from neutrality do not always imply losses to the country implementing the BAT, and depend on the details of the deviation, as demonstrated by Barbiero and others (2017). In the next section, I sketch a simple model to illustrate these arguments analytically.

\section{The Benchmark Case for Neutrality}

In this section, I lay out a simple general equilibrium model with a BAT to demonstrate neutrality. This is a static version of the model of Barbiero and others (2017), with simplifying restrictions on functional forms. In this model, the world has two regions, Home $(H)$ and Foreign $(F)$, and the BAT is implemented in $H$. I assume all foreign variables to be exogenous and unchanging, consistent with assuming that $H$ is small relative to $F$. The results are unchanged if, instead, both regions are large. To simplify exposition, I use specific functional forms; however, the predictions apply more generally, as demonstrated by Barbiero and others (2017). I focus here on 
the BAT, but the results also apply to the other uniform border taxes listed in the introduction.

The model has four agents: "bundlers," which combine domestically produced and imported goods to produce a nontraded good that is used for household consumption and as an intermediate input for production; households, which consume the nontraded good and supply labor; firms, which produce a unique variety of traded goods that are sold in $H$ and $F$; and governments, which tax and transfer.

I start by assuming that prices and wages are fully flexible, and I then consider the case of sticky prices.

\section{I.A. Bundlers}

The nontraded consumption good $C$ and intermediate good $X$ are produced by competitive firms called "bundlers," which combine domestic and imported goods using the technology

$$
\begin{gathered}
F=F_{H H}^{1-\theta} F_{F H}^{\ominus}, \\
F_{H H}=\left(\int_{\omega} F_{H H}(\omega)^{\frac{\sigma-1}{\sigma}}\right)^{\frac{\sigma}{\sigma-1}},
\end{gathered}
$$

where $F_{H H}$ is a bundle of domestic varieties $\omega$, under the assumption of constant elasticity of substitution. ${ }^{1}$

The price of bundle $F$ is given by

$$
\begin{gathered}
P=\frac{P_{H H}^{1-\theta} P_{F H}^{\theta}}{(1-\theta)^{1-\theta} \theta^{\theta}}, \\
P_{F H}=\frac{P_{F H}^{*} \varepsilon}{1-\imath \tau},
\end{gathered}
$$

where $P_{H H}$ is the price of the domestically produced good, $P_{F H}^{*}$ is the price of the imported good in $F$ currency, $\varepsilon$ is the exchange rate defined as $H$ currency per unit of $F$ currency so that an increase in $\varepsilon$ is a depreciation of $H$ currency, $\tau$ is the corporate tax rate, and $\imath=1$ with a BAT and $\imath=0$ otherwise. This formulation captures the fact that under a BAT, imported goods are subject to taxation relative to domestically produced goods

1. The analysis remains unchanged if instead I assume that the firms have monopoly power and charge markups. 
by the margin of the corporate tax rate $\tau$. The demand for domestic and imported goods is

$$
\begin{gathered}
F_{H H}=(1-\theta) \frac{P}{P_{H H}}(C+X), \\
F_{F H}=\theta \frac{P}{P_{F H}}(C+X), \\
F_{H H}(\omega)=F_{H H}\left(\frac{P_{H H}(\omega)}{P_{H H}}\right)^{-\sigma} .
\end{gathered}
$$

\section{I.B. Households}

Households consume $C$ and supply labor $N$, and they maximize utility $U(C, N)=\log C-N$ subject to the budget constraint

$$
P C+\varepsilon B^{*}=W N+\Pi+T,
$$

where $B^{*}$ is the inherited net foreign debt in foreign currency, $\Pi$ is after-tax corporate profits, $W$ is the wage rate, and $T$ is transfers from the government. From the optimality of the labor-leisure decision, we have

$$
-\frac{U_{N}}{U_{C}}=\frac{W}{P} \rightarrow P C=W
$$

In a static environment, there are no other decisions to be made.

\section{I.C. Firms}

Firms produce a unique variety of goods $\omega$, which they sell domestically and export. The production function is given by

$$
Y(\omega)=A L(\omega)^{1-\alpha} X(\omega)^{\alpha},
$$

where $L$ is labor, $X$ is the intermediate input, and $A$ is productivity. The firm's profits are given by

$$
\begin{aligned}
\Pi(\omega)= & (1-\tau)\left(P_{H H}(\omega) Y_{H H}(\omega)+P_{H F}(\omega) Y_{H F}(\omega)-M C \cdot Y(\omega)\right) \\
& +\imath \tau P_{H F}(\omega) Y_{H F}(\omega),
\end{aligned}
$$

where $\tau$ is the corporate tax rate, $P_{H H}(\omega)$ and $Y_{H H}(\omega)$ are the price the firm sets and the quantity it sells in the $H$ market (to $H$ bundlers), $P_{H F}(\omega)$ and 
$Y_{H F}(\omega)$ are the price and quantity sets for the $F$ market, $M C$ is the (constant) marginal cost of production, and $Y(\omega)=Y_{H H}(\omega)+Y_{H F}(\omega)$.

$$
M C=\frac{1}{\alpha^{\alpha}(1-\alpha)^{1-\alpha}}\left(\frac{W^{1-\alpha} P^{\alpha}}{A}\right) .
$$

With a BAT, $\mathrm{l}=1$, and, consequently, export revenues are not taxed. This is the second margin on which the BAT works. The optimality conditions for hiring labor and intermediate inputs satisfy

$$
\begin{gathered}
(1-\alpha) \frac{Y}{L}=\frac{W}{M C}, \\
\alpha \frac{Y}{X}=\frac{P}{M C} .
\end{gathered}
$$

Market clearing will imply that $F_{H H}=Y_{H H}$.

\section{I.D. Government}

From the government's budget constraint, we have

$$
T=\frac{\tau}{1-\tau} \Pi-\imath \frac{\tau}{1-\tau}\left(P_{H F} Y_{H F}-\varepsilon P_{F H}^{*} Y_{F H}\right) .
$$

Combining the government's and households' budget constraints, we have the condition

$$
\varepsilon B^{*}=P_{H F} Y_{H F}-\varepsilon P_{F H}^{*} Y_{F H} .
$$

That is, the debt needs to be repaid by running a trade surplus.

Proposition 1. When prices and wages are flexible, the equilibrium with a BAT $(l=1)$ has the same allocation as the equilibrium without a BAT $(l=0)$, but with a higher relative domestic wage and more appreciated real exchange rate. That is,

$$
\begin{aligned}
& \frac{\varepsilon^{\prime} W^{*}}{W^{\prime}}=(1-\tau) \frac{\varepsilon W^{*}}{W}, \\
& \frac{\varepsilon^{\prime} P^{*}}{P^{\prime}}=(1-\tau) \frac{\varepsilon P^{*}}{P},
\end{aligned}
$$

where the primes (') refer to the BAT equilibrium. Recall that foreign variables like $W^{*}$ are assumed to be unchanged by the BAT given our 
assumption of a small open economy. The results, however, do not depend on this restriction.

A detailed proof is provided in the appendix. Basically, a BAT is associated with an increase in relative wages at home, that is, an increase in $\frac{W}{\varepsilon W^{*}}$,

$$
\frac{W^{\prime}}{\varepsilon^{\prime} W^{*}}=\frac{\left(\frac{W^{\prime}}{P^{*}}\right)}{\left(\frac{\varepsilon^{\prime} W^{*}}{P^{*}}\right)}=\left(\frac{1}{1-\tau}\right) \frac{W}{\varepsilon W^{*}},
$$

where the last equality follows from the fact that real wages $(W / P)$ are unchanged across the two equilibria with the same level of consumption, which follows from the labor-leisure decision (equation 6). The increased demand for $H$ goods following a BAT leads to an increase in relative wages at home that perfectly offsets the tax advantage. Demand at $H$ and $F$ therefore remains unchanged as posttax relative prices in $H$ and $F$ remain unchanged; that is,

$$
\begin{gathered}
\frac{P_{H H}^{\prime}}{P^{\prime}}=\mu\left(\frac{W^{\prime}}{P^{\prime}}\right)^{1-\alpha}=\mu\left(\frac{W}{P}\right)^{1-\alpha}=\frac{P_{H H}}{P}, \\
\frac{P_{H F}^{* \prime}}{P^{*}}=\frac{(1-\tau) \mu\left(\frac{W^{\prime}}{P^{\prime}}\right)^{1-\alpha}}{\left(\frac{\varepsilon^{\prime}}{P^{\prime}}\right) P^{*}}=\frac{\mu\left(\frac{W}{P}\right)^{1-\alpha}}{\left(\frac{\varepsilon}{P}\right) P^{*}}=\frac{P_{H F}^{*}}{P^{*}},
\end{gathered}
$$

where $\mu=\frac{\sigma}{\sigma-1}$ is the constant markup. ${ }^{2}$ Consequently, $Y_{H H}$ and $Y_{H F}$ remain unchanged. Relatedly, the terms of trade (TOT) ratio, which measures the relative price of imports to exports at the border, remains unchanged:

$$
T O T=\frac{P^{*}}{P_{H F}^{* \prime}}=\frac{P^{*}}{(1-\tau) \mu\left(\frac{W^{\prime}}{P^{\prime}}\right)^{1-\alpha}\left(\frac{\varepsilon^{\prime}}{P^{\prime}}\right)}=\frac{P^{*}}{\mu\left(\frac{W}{P}\right)^{1-\alpha}\left(\frac{\varepsilon}{P}\right)}=\frac{P^{*}}{P_{H F}^{*}} .
$$

2. Because of symmetry across firms, I drop the $\omega$ reference. 
From the consolidated budget constraint, we have

$$
C^{\prime}=\frac{\left(\frac{\varepsilon^{\prime}}{P^{\prime}}\right)}{1-\imath \tau} B^{*}=\frac{W^{\prime}}{P^{\prime}} N+\frac{\left(\frac{\Pi^{\prime}}{P^{\prime}}\right)}{1-\tau} .
$$

With real wages and real after-tax profits unchanged, the real appreciation offsets the BAT, leaving the real allocation unchanged. ${ }^{3}$

If we continue to assume flexible prices and introduce money into the model-picking a particular nominal equilibrium, where the monetary authority targets a 0 percent inflation rate, so $P=1$ - the implication in this case is for the nominal exchange rate to appreciate one-to-one with the tax.

Proposition 2. If prices are flexible and the monetary authority targets a fixed $P=1$, then $\frac{\varepsilon}{\varepsilon^{\prime}}=\frac{1}{1-\tau}$. That is, the nominal exchange rate does all the work.

In the event that the U.S. corporate tax rate is reduced to 20 percent, the scenario with a BAT involves a U.S. dollar appreciation of 25 percent, as compared with one without a BAT. This 25 percent number has been reported frequently in discussions of the BAT.

\section{Departures from the Benchmark}

In this section, I discuss departures from the assumptions that drive the Lerner symmetry result, and evaluate the conditions under which neutrality continues to hold.

\section{II.A. Sticky Prices and Wages}

In the previous section, I assumed flexible prices. In this section, I demonstrate that when the exchange rate changes by the same magnitude as the BAT — that is, $\frac{\varepsilon^{\prime}}{\varepsilon}=(1-\tau)$ - then two forms of price stickiness, namely, producer currency pricing and local currency pricing, maintain neutrality, while a third, dollar currency pricing, which arguably is a more realistic description of price stickiness in international trade, leads to a breakdown of neutrality.

3. This can be demonstrated using equation 8 and the relation that $\frac{P_{H F}^{\prime}}{P^{\prime}}=(1-\tau)\left(\frac{P_{H F}}{P}\right)$. 
PRODUCER CURRENCY PRICING The Mundell-Fleming benchmark assumes that prices are sticky in the producer's currency and the law of one price holds, that is, $P_{H H}^{\prime}=\bar{P}_{H H}$ and $P_{H F}^{\prime}=(1-\tau) \bar{P}_{H H}$. In this case, the nominal exchange rate appreciation is sufficient to mimic the flexible price equilibrium:

$$
T O T^{\prime}=\frac{\varepsilon^{\prime} \bar{P}_{F H}^{*}}{(1-\tau) \bar{P}_{H H}}=\frac{\varepsilon \bar{P}_{F H}^{*}}{\bar{P}_{H H}}=T O T .
$$

The prices of imports in $H$ and exports to $F$, given by

$$
\begin{gathered}
P_{F H}^{\prime}=\frac{\bar{P}_{F H}^{*} \varepsilon^{\prime}}{1-\tau}, \\
P_{H F}^{* \prime}=\frac{(1-\tau) \bar{P}_{H H}}{\varepsilon^{\prime}},
\end{gathered}
$$

are unchanged, as the exchange rate appreciation fully offsets the higher tax on imports; and while the subsidy lowers the home currency price at which $H$ sells to $F$, the exchange rate depreciation of $F$ currency raises its price in foreign currency with a complete offset. There is therefore no change in demand for $H$ goods from either region. Of particular importance, this result follows from the symmetry in pass-through (100 percent) of the exchange rate and the BAT into buyers' prices $\left(P_{F H}^{\prime}\right.$ and $\left.P_{H F}^{* \prime}\right)$.

LOCAL CURRENCY PRICING The other extreme is where the prices that buyers face in the destination market are preset in the destination market's currency. That is, $P_{F H}^{\prime}=\bar{P}_{F H}$ and $P_{H F}^{* \prime}=\bar{P}_{H F}^{*}$ are sticky. In this case, neither the exchange rate nor the BAT has any effect on the prices buyers face, and therefore has no effect on demand for them. Similarly, there is no change in the terms of trade,

$$
T O T^{\prime}=\frac{(1-\tau) \bar{P}_{F H}}{\varepsilon^{\prime} \bar{P}_{H F}^{*}}=\frac{\bar{P}_{F H}^{*}}{\varepsilon \bar{P}_{H F}^{*}}=T O T,
$$

where the numerator is the price $F$ sellers receive and the denominator is the price $H$ sellers receive. Again, there is symmetry in the pass-through of the exchange rate and the BAT into export and import prices of buyers, with both being zero in this case.

DOLLAR CURRENCY PRICING As described by Gopinath (2015) and Camila Casas and others (2017), traded goods in world trade are dominated by dollar pricing. Gopinath and Roberto Rigobon (2008) and Gopinath, 
Itskhoki, and Rigobon (2010) report that about 94 percent of U.S. imports and 97 percent of U.S. exports are priced and sticky in dollars for durations of 10 to 12 months. Further, even conditional on a price change, the passthrough into dollar prices is low.

In this more realistic case, dollar prices at the border are sticky. The net-of-tax prices faced by buyers at $H$ and $F$ are then

$$
\begin{gathered}
P_{F H}^{\prime}=\frac{\bar{P}_{F H}^{b}}{(1-\tau)}, \\
P_{H F}^{* \prime}=\frac{\bar{P}_{H F}^{b}}{\varepsilon}, \\
\frac{P_{F H}^{\prime}}{P^{\prime}}=\frac{1}{(1-\theta)^{1-\theta} \theta^{\theta}}\left(\frac{\left.\left(\frac{\bar{P}_{F H}^{b}}{1-\tau}\right)\right)^{1-\theta}}{\bar{P}_{H H}},\right. \\
\frac{P_{H F}^{* \prime}}{P^{*}}=\frac{\bar{P}_{H F}^{b}}{\varepsilon P^{*}},
\end{gathered}
$$

where the superscript $b$ stands for the border, and I have used the relations $P=\frac{P_{H H}^{\mathrm{I}-\theta} P_{F H}^{\theta}}{(1-\theta)^{1-\theta} \theta^{\theta}}$ and $P_{H H}=\bar{P}_{H H}$.

In this case, there is asymmetry in the pass-through of exchange rates and taxes into demand-relevant prices. The exchange rate appreciation does not affect the border price of imports in dollars and, consequently, net-of-tax prices rise, leading to a shift in demand away from imports. In the case of exports, the border price in dollars does not change with the tax rate and, consequently, the dollar's appreciation makes the foreign currency price of exports rise, leading to a drop in demand for U.S. exports. Exchange rate appreciation cannot undo the tax change leading to a drop in imports and exports. As shown by Barbiero and others (2017), the negative effect on overall trade (the sum of exports and imports) is large, while the effect on the trade balance is small.

\section{II.B. Saving and Borrowing}

The derivation in section I was for a static environment without borrowing and lending. Neutrality is preserved as long as all assets and liabilities are denominated in foreign currency and the BAT's implementation 
is one time and unanticipated. To illustrate this, consider the case when only foreign currency bonds that pay a gross interest rate of $R_{t}^{*}$ are traded internationally. From the Euler equation, we have

$$
\beta R_{t}^{*} E_{t}\left[\frac{C_{t}}{C_{t+1}} \cdot \frac{\varepsilon_{t} P_{t}}{\varepsilon_{t+1} P_{t+1}}\right]=1
$$

When the BAT is one time and unanticipated, the real exchange rate appreciates permanently; that is, $\frac{\varepsilon_{t}}{P_{t}}=\frac{\varepsilon_{t+1}}{P_{t+1}}$, and there is no impact on $C$ through the Euler equation. If, conversely, there are predictable changes in the real exchange rate because of expectations for the BAT or because of gradual adjustment in rates or reversals, then neutrality does not hold as the saving and borrowing decisions of $H$ agents are altered.

A second departure from neutrality is when $H$ trades financial instruments in $H$ currency. Suppose that $H$ has debt in $H$ currency, similar to the case of the United States, whose liabilities are overwhelmingly in dollar-denominated bonds. In this case, the consolidated budget constraint in equation 10 is

$$
C^{\prime}+\frac{\left(\frac{\varepsilon^{\prime}}{P^{\prime}}\right)}{1-\imath \tau} B^{*}+\frac{\left(\frac{1}{P^{\prime}}\right)}{1-\imath \tau} B=\frac{W^{\prime}}{P^{\prime}} N+\frac{\left(\frac{\Pi^{\prime}}{P^{\prime}}\right)}{1-\tau} .
$$

Even with flexible prices, the BAT leads to an increase in transfers to $F$ that is equivalent to the dollar's appreciation, which leads to a breakdown in neutrality. Because U.S. foreign assets are mostly denominated in foreign currency, while foreign liabilities are almost entirely in dollars, this generates a one-time transfer to the rest of the world and a capital loss for the United States of about 13 percent of U.S. annual GDP.

\section{II.C. Monetary Policy}

The real consequences of a BAT depend crucially on the stance of monetary policy. Assumptions that support neutrality generate zero inflation and a zero output gap. Therefore, as long as the monetary authority only targets inflation and the output gap, neutrality is preserved. With interest rates unchanged, a one-time and permanent exchange appreciation is consistent with uncovered interest parity.

If, conversely, monetary policy targets the exchange rate, then we no longer have neutrality. This is indeed the case for a fiscal devaluation, 
whereby border taxes can stimulate the economy in a fixed-exchangerate regime.

In the case where neutrality breaks down, the prediction for the exchange rate is less straightforward. Barbiero and others (2017) demonstrate that the extent of appreciation depends on trade openness and the relative magnitude of price and wage stickiness in nonlinear ways. For parameters calibrated to the United States, Barbiero and others (2017) find that even when dollar pricing and $H$ currency international assets lead to departures from neutrality, the nominal exchange rate change is quantitatively close to $(1-\tau)$.

\section{II.D. Fiscal Revenues}

When a BAT is neutral, it is associated with an undistortive (lumpsum) transfer from the U.S. private sector to the government budget, in proportion to the trade deficit:

$$
T^{\prime}-T=\frac{\tau}{1-\tau}\left(P_{H F}^{\prime} Y_{H F}-\varepsilon^{\prime} P_{F H}^{*} Y_{F H}\right)=\tau\left(P_{H F} Y_{H F}-\varepsilon P_{F H}^{*} Y_{F H}\right) .
$$

The fiscal revenues are positive in periods of trade deficits, and they are negative in periods of trade surpluses. If, as in the United States, the country has a negative net foreign assets position, then it must imply that the present discounted value of transfers to the government will be negative, because to preserve long-run solvency, the present discounted value of trade surpluses must be positive.

\section{A P PENDIX}

Proposition 1. When prices and wages are flexible, the equilibrium with a BAT $(\mathrm{l}=1)$ has the same allocation as the equilibrium without a BAT $(l=0)$, but with a higher relative domestic wage and more appreciated real exchange rate. That is,

$$
\begin{gathered}
\frac{\varepsilon^{\prime} W^{*}}{W^{\prime}}=(1-\tau) \frac{\varepsilon W^{*}}{W}, \\
\frac{\varepsilon^{\prime} P^{*}}{P^{\prime}}=(1-\tau) \frac{\varepsilon P^{*}}{P},
\end{gathered}
$$

where the primes (') refer to the BAT equilibrium.

Proof. I list here the system of equations and variables, where all $H$ variables are scaled by the price level, that is, $\tilde{X}=X / P$. 


$$
\begin{aligned}
& C=\widetilde{W} \\
& \tilde{P}_{H H}=\mu \widetilde{W}^{1-\alpha} \\
& \tilde{P}_{H F}=(1-\imath \tau) \mu \widetilde{W}^{1-\alpha} \\
& \tilde{P}_{F H}=\frac{P_{F H}^{*} \tilde{\varepsilon}}{1-\imath \tau} \\
& \tilde{P}_{H H}^{1-\theta} \tilde{P}_{F H}^{\theta}=1 \\
& Y_{H H}=(1-\theta) \frac{C+X}{\tilde{P}_{H H}} \\
& Y_{F H}=\theta \frac{C+X}{\tilde{P}_{F H}} \\
& Y_{H F}=\theta \frac{\tilde{\varepsilon}}{\tilde{P}_{F H}} P^{*}\left(C^{*}+X^{*}\right) \\
& (1-\alpha) \frac{Y}{N}=\frac{\widetilde{W}}{\widetilde{M C}} \\
& \alpha \frac{Y}{X}=\frac{1}{\widetilde{M C}} \\
& \widetilde{M C}=\frac{1}{\alpha^{\alpha}(1-\alpha)^{1-\alpha}} \widetilde{W}^{1-\alpha} \\
& \widetilde{\Pi}=(1-\tau)\left(\tilde{P}_{H H} Y_{H H}+\tilde{P}_{H F} Y_{H F}-\widetilde{M C} \cdot Y\right)+\imath \tau \tilde{P}_{H F} Y_{H F} \\
& C+\frac{\tilde{\varepsilon}}{1-\imath \tau} B^{*}=\widetilde{W} N+\frac{\widetilde{\Pi}}{1-\tau} \\
& Y=Y_{H H}+Y_{H F}
\end{aligned}
$$

This is a system of 14 equations in 14 unknowns: $C, \widetilde{W}, \tilde{P}_{H H}, \tilde{P}_{H F}, \tilde{P}_{F H}, Y_{H H}$, $X, Y_{F H}, Y_{H F}, Y, N, \widetilde{\varepsilon}, \widetilde{M C}$, and $\widetilde{\Pi}$. The proof follows simply from recognizing that the real allocations are identical in the case with and without a BAT, as long as $\frac{\varepsilon^{\prime}}{\varepsilon}=(1-\tau)$.

ACKNOWLEDGMENTS I thank Oleg Itskhoki for very helpful conversations. 


\section{References}

Auerbach, Alan, Michael P. Devereux, Michael Keen, and John Vella. 2017. "Destination-Based Cash-Flow Taxation." Working Paper no. 17/01. Oxford: Oxford University, Centre for Business Taxation.

Barbiero, Omar, Emmanuel Farhi, Gita Gopinath, and Oleg Itskhoki. 2017. "The Economics of Border Adjustment Tax." Working paper. http://www.princeton. edu/ itskhoki/papers/BAT.pdf

Casas, Camila, Frederico J. Díez, Gita Gopinath, and Pierre-Olivier Gourinchas. 2017. "Dominant Currency Paradigm: A New Model for Small Open Economies." Working paper. https://scholar.harvard.edu/files/gopinath/files/paper_ 080217.pdf

Committee on Finance and Industry. 1931. "Report of the Committee on Finance and Industry." London: HM Stationary Office. http://filestore.nationalarchives. gov.uk/pdfs/small/cab-24-222-CP-160-3.pdf

Farhi, Emmanuel, Gita Gopinath, and Oleg Itskhoki. 2014. "Fiscal Devaluations." Review of Economic Studies 81, no. 2: 725-60.

- 2017. "Trump's Tax Plan and the Dollar.” Project Syndicate, January 3.

Feldstein, Martin, and Paul Krugman. 1990. "International Trade Effects of ValueAdded Taxation." In Taxation in the Global Economy, edited by Assaf Razin and Joel Slemrod. University of Chicago Press.

Gopinath, Gita. 2015. “The International Price System.” In Economic Policy Symposium Proceedings: Inflation Dynamics and Monetary Policy. Jackson Hole, Wyo.: Federal Reserve Bank of Kansas City.

Gopinath, Gita, Oleg Itskhoki, and Robert Rigobon. 2010. "Currency Choice and Exchange Rate Pass-Through." American Economic Review 100, no. 1: 304-36.

Gopinath, Gita, and Roberto Rigobon. 2008. "Sticky Borders.” Quarterly Journal of Economics 123, no. 2: 531-75.

Grossman, Gene M. 1980. "Border Tax Adjustments: Do They Distort Trade?" Journal of International Economics 10, no. 1: 117-28.

Lerner, Abba P. 1936. "The Symmetry between Import and Export Taxes." Economica 3, no. 11: 306-13. 